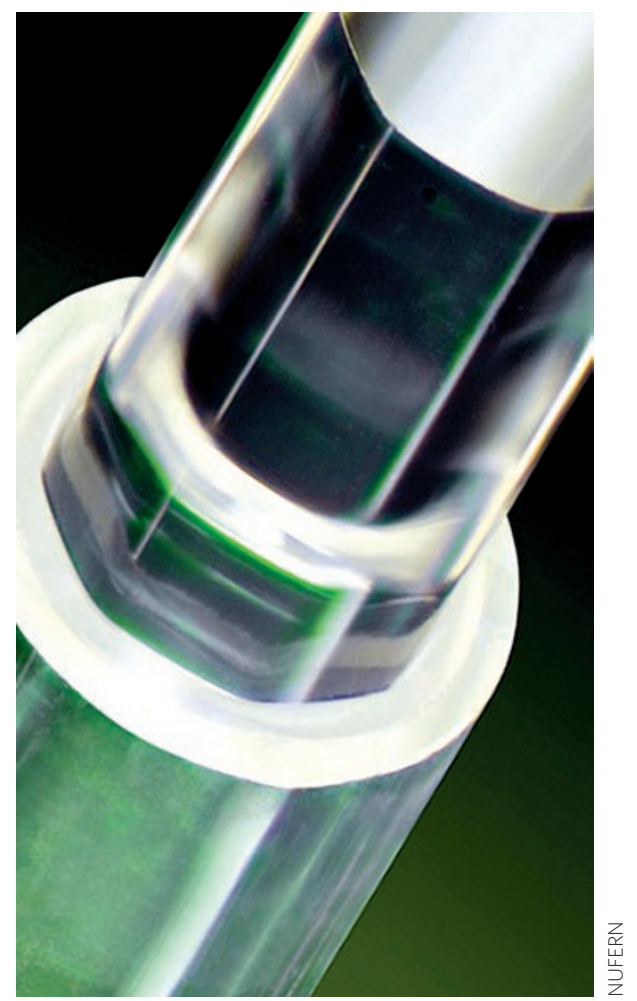

COVER IMAGE

Nufern has developed a family of rare-earth-doped fibres that has significant potential for high-power and industrial applications.

NPG ASIA-PACIFIC

Chiyoda Building 2-37

Ichigayatamachi, Shinjuku-ku, Tokyo

162-0843 Japan

T: +81332678751

F: +81332678746

naturephoton@nature.com

EDITOR

OLIVER GRAYDON

PRODUCTION EDITOR

CHRIS GILLOCH

COPY EDITOR

JAMES BAXTER

ART EDITOR

TOM WILSON

SALES ACCOUNT MANAGER

KEN MIKAMI

$\mathrm{T}:+81332678751$

ADVERTISING DIRECTOR

GEORGE LUI

$\mathrm{T}:+14157813804$

ADVERTISING MANAGER

SIMON ALLARDICE

$\mathrm{T}:+14154039034$

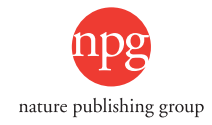

\section{Fibres get special}

O ptical fibre - a technology wellknown to have revolutionized the telecommunications industry - is now proving to have important roles in applications such as sensing, biomedicine, defence, security and the development of novel light sources. A range of optical fibre designs and materials are now being developed to meet the needs of both established and growing industries. This month's Technology Focus covers some of the specialty optical fibres available today and gives insight into their unique applications.

Developed in the early 1990s, photonic crystal fibre is praised for its unique range of unconventional properties. NKT Photonics in Denmark, which claims to be the world's only commercial supplier of photonic crystal fibre, explains on page 464 how it has used photonic crystal fibre to develop industrially reliable supercontinuum sources and replace traditional solid-state crystals in the highpower pulsed laser market.

Chalcogenide optical fibre based on sulphur, selenium and/or tellurium offers sufficient stability and transmission for applications at infrared wavelengths. Dan Hewak from the University of Southampton in the UK explains on page 474 that although high-quality chalcogenide fibre can already be fabricated, the main challenge is not the drawing process but rather achieving high purity levels in the glass. He believes that attaining this goal will require new glass-melting technology and reproducible, reliable fabrication techniques.

Modifying a fibre's design or constituent materials is another way of diversify its applications. On page 470, Victor Kopp and Azriel Genack from Chiral Photonics in the USA describe how applying twist during the fabrication of an optical fibre can provide chiral properties such as polarization- and wavelength-selectivity, which are attractive for polarization control, harsh-environment sensing and photonic integrated circuits. On page 466, Bryce Samson, Adrian Carter and Kanishka Tankala from Nufern in the USA say that fibres doped with rare-earth materials can improve the output power of fibre lasers to beyond $1 \mathrm{~kW}$. On page 468 , Andy Gillooly from Fibercore in the UK with gratings - a periodic variation in the core's refractive index - can aid the growth of sensor and fibre laser markets.

Today's optical fibres are far more sophisticated than those of decades past, and it is clear that their potential applications now extend well beyond telecommunications. explains how photosensitive fibres inscribed

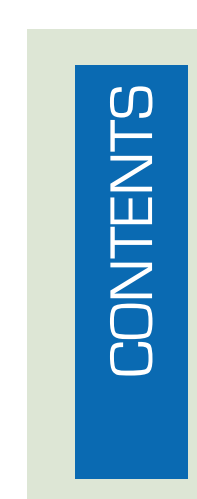

\section{BUSINESS NEWS}

Management buyouts and medical market opportunities

\section{RESEARCH HIGHLIGHTS}

Our choice from the recent literature

\section{PROFILE}

Photonic crystal pioneer

\section{INDUSTRY PERSPECTIVE}

Doped fibres: Rare-earth fibres power up

Bryce Samson, Adrian Carter and Kanishka Tankala

Photosensitive fibres: Growing gratings

Andy Gillooly

Chiral fibres: Adding twist

Victor I. Kopp and Azriel Z. Genack

\section{PRODUCT HIGHLIGHTS}

Metal-coated fibres, double-cladding designs and more 